\title{
Adsorptive Behavior of Prepared Metal-Organic Framework Composites on Phosphates in Aqueous Solutions
}

\author{
Yan Zhao, ${ }^{1}$ Hui-xuan Guo, ${ }^{2}$ Hong-guang Han, ${ }^{3}$ Jia-qi Zhang $\mathbb{D}^{2},{ }^{2}$ and Xiao-min $\mathrm{Hu}^{1}$ \\ ${ }^{1}$ College of Resources and Civil Engineering, Northeastern University, Shenyang 110819, China \\ ${ }^{2}$ Shenyang Saisi Environmental Engineering Design \& Research Center, Shenyang 110000, China \\ ${ }^{3}$ Department of Cardiovascular Surgery, General Hospital of Northern Theater Command, Shenyang 110000, China
}

Correspondence should be addressed to Jia-qi Zhang; 1914143645@qq.com

Received 29 July 2020; Accepted 9 November 2020; Published 4 February 2021

Academic Editor: Adrián Bonilla-Petriciolet

Copyright ( 92021 Yan Zhao et al. This is an open access article distributed under the Creative Commons Attribution License, which permits unrestricted use, distribution, and reproduction in any medium, provided the original work is properly cited.

As an efficient water treatment method for treating dilute solution systems, electrosorption is promising for the separation and recovery of organic compounds, wastewater treatment, and deep purification of water. Here, two types of UiO-66 samples were prepared using the solvothermal synthesis method, and the effects of different regulators on the microstructure of materials were compared using the various characterization methods. The electrochemical properties of the activated carbon and two types of materials were tested by cyclic voltammetry and AC impedance spectroscopy, and the desalination effect of the materials on phosphate was investigated. The UiO-66 material with uniform-size particles, smaller-size particles, and more surface adsorption sites exhibited better phosphate removal and adsorption capacity. It was found that the desalination process of the UiO-66 material is reversible, and the adsorbent material can be reused, which is advantageous for engineering applications.

\section{Introduction}

Phosphorus pollution has become a common and prominent problem in water pollution $[1,2]$. Chemical coagulation precipitation is the most widely method for phosphorus removal, and it is stable and reliable while at the same time strongly affected by $\mathrm{pH}$ [3]. The solid sludge generated using this method causes secondary environmental risks [4]. The biological approach toward phosphorus removal is relatively economical, does not affect the removal effect of total nitrogen, and does not generate large amounts of chemical sludge, compared with the chemical precipitation method [5]. However, the performance of the biological method is easily affected by the influent water quality, $\mathrm{pH}$, dissolved oxygen concentration, sludge residence time, and temperature. In general, biological phosphorus removal alone does not meet the discharge requirements of the effluent concentration below $0.5 \mathrm{mg} / \mathrm{L}$ of phosphorus and is usually accompanied by chemical phosphorus removal $[6,7]$. Crystallizationbased phosphorus removal is of significant interest in the field of wastewater phosphorus removal and phosphorus recovery and constitutes a reliable advanced method for treating phosphorus-containing wastewater [8-10]. However, the crystallization approach requires the influent to be alkaline and also requires a certain concentration of calcium ions [11].

Compared with the above methods, adsorption-based methods are considered to be among the most promising for phosphate removal, owing to their relatively simple operation, fast and efficient removal effect, reusability, and low operating cost; an example is phosphate removal using the "green roof" scheme. Therefore, significant research effort has been made for developing highly selective and costeffective adsorbents, for the removal of excess phosphate from water; examples include activated carbon, iron oxides, and zeolite [12-15]. Recently, metal-organic frameworks (MOFs) have been widely used for efficient removal and recovery of phosphorus from wastewater, owing to their remarkable phosphate adsorption selectivity and chelating potential. Compared with traditional adsorbents, MOFs have more advantages, such as porosity and adjustable pore size, large specific surface area, structural diversity, and presence 
of unsaturated metal sites [16]. Owing to the low chemical and hydrothermal stability of MOFs, the development of MOFs had been limited to a certain extent until the development of UiO-66 synthesis improved the situation [17-19]. $\mathrm{UiO}-66$ is a type of the MOF material prepared with $\mathrm{Zr}^{4+}$ as the central metal ion and with terephthalic acid as the ligand $[20,21]$. UiO-66 has good thermal and chemical stability and can form tetrahedral and octahedral cage structures [22]. Qiu et al. proposed a novel method for immobilizing water-stable MOF UiO-66 nanoparticles within modified wheat straws, using in situ hydrothermal synthesis, with excellent selectivity and preference toward phosphate [23]. Lin et al. used an amine-substituted ligand to prepare $\mathrm{UiO}-66-\mathrm{NH}_{2}$, which was capable of adsorbing phosphate in urine and completely removing diluted phosphate in urine [24]. Min et al. synthesized the novel lanthanum-doped UiO-66 (La-UiO-66), which was proved to have a greater adsorption capacity for phosphate. The maximum adsorption capacity was $348.43 \mathrm{mg} / \mathrm{g}$ for $0.2 \mathrm{La}-$ UiO-66 [25]. Wang et al. analyzed the phosphate adsorption mechanism in $\mathrm{HCl}-\mathrm{UiO}-66$ and $\mathrm{HCl}-\mathrm{NH} 2-\mathrm{UiO}-66$ by testing the relationship between the adsorbed phosphate and released linker in the adsorption process [26].

Compared with the traditional desalination technology, the electrosorption desalination technology has the advantages of low energy consumption, high water utilization rate, no secondary pollution, simple operation and maintenance, and strong antipollution ability. It is thus an effective and economical desalination technology [27]. The electrochemical adsorption technology at home and abroad has been mainly focused on the electrodes made of graphite, activated carbon particles, activated carbon fibers, and carbon aerogels [28-30].

Based on the advantages of $\mathrm{UiO}-66$, we synthesized $\mathrm{UiO}-$ 66 using two regulators. The synthesis of MOFs has gone through three stages: the first stage is the diffusion method, which can obtain the larger size single crystal, but takes a relatively long time; the second stage is the solvothermal synthesis method, which can control the size, shape, and crystallinity of MOF materials (especially single crystal); the last stage is the microwave-assisted method, ultrasonic method, and mechanical grinding method which are conducive to rapid batch synthesis of MOF materials. Therefore, in this paper, two types of UiO-66 samples were prepared using the solvothermal synthesis method. The morphologies of the two synthesized UiO-66 materials were analyzed and compared using X-ray diffraction (XRD), scanning electron microscopy (SEM), and transmission electron microscopy (TEM). The electrochemical properties of activated carbon and the two synthesized UiO-66 materials were tested using cyclic voltammetry and AC impedance spectroscopy. The adsorption and electrosorption characteristics of the two synthesized UiO-66 materials were also investigated in terms of the desalination effect of phosphate.

\section{Materials and Methods}

2.1. Preparation of UiO-66. In this work, UiO-66 was prepared by solvothermal synthesis. $\mathrm{ZrCl}_{4}(0.63 \mathrm{~g}, 2.7 \mathrm{mmol})$ as a metal source and terephthalic acid $(0.63 \mathrm{~g}, 3.8 \mathrm{mmol})$ as an organic ligand were added to an organic solution of $\mathrm{N}, \mathrm{N}$-dimethylformamide $(50 \mathrm{~mL})$ while stirring using a magnetic stirrer. Then, $37 \%$ acetic acid $(5 \mathrm{~mL})$ and $37 \%$ hydrochloric acid $(5 \mathrm{~mL})$ were added as regulators. After uniform stirring, the solution was placed in a Teflon-lined reaction vessel $(100 \mathrm{~mL})$, and the reactor was heated in a drying chamber at $120^{\circ} \mathrm{C}$ for $24 \mathrm{~h}$. Next, the solution was allowed to cool to room temperature, an appropriate amount of the methanol solution was added, and the solution was let to stand for 6 hours. The reaction liquid with the acetic acid as the regulator was centrifuged three times, and a suitable amount of the methanol solution was added each time, finally yielding UiO-66 (acetic acid) as the initial product. The reaction liquid with the hydrochloric acid as the regulator was filtrated three times, and a suitable amount of the methanol solution was added each time, finally yielding UiO-66 (hydrochloric acid) as the initial product. Finally, white-powder UiO-66 samples were obtained by drying the initial product in a drying chamber at $100^{\circ} \mathrm{C}$ for 20 hours.

2.2. Characterization Analysis of UiO-66. The phase purity and stability of framework structure of two UiO-66 samples synthesized using the two regulators were analyzed in terms of the XRD (X'Pert Pro, PANalytical, Holland), the radiation source was $\mathrm{Cu} \mathrm{K} \alpha$-ray $(\lambda=1.5478 \AA$ ), voltage was $40 \mathrm{kV}$, current was $40 \mathrm{~mA}$, scanning angle $2 \theta$ was $5^{\circ}$ to $90^{\circ}$, and the test was carried out at room temperature. The amount of sample used in the test was about $20 \mathrm{mg}$. The morphological differences between the two samples were analyzed in terms of SEM (SSX-550, Shimadzu, Japan), and the magnification was $70 \mathrm{k}$. The samples were also analyzed by the TEM (Tecnai $\mathrm{G}^{2} 20$, Hillsboro, America), and the acceleration voltage was $200 \mathrm{kV}$.

2.3. Electrochemical Performance. The electrochemical properties of the prepared UiO-66 samples were characterized and analyzed using cyclic voltammetry and AC impedance measurements. Commercial activated carbon or UiO-66 samples, a conductive agent (carbon black), and a polytetrafluoroethylene dilute binder (PVDF) were mixed evenly, according to the mass ratio of $8: 1: 1$. A suitable amount of the dimethylacetamide solvent was added to mix for 4 hours, under magnetic stirring, to form a slurry with a certain viscosity. The slurry was uniformly coated on a rectangular nickel foam collector and dried at $100^{\circ} \mathrm{C}$ for 20 hours. Commercial carbon and UiO-66 samples' coating electrodes were obtained. The cyclic voltammetry test used a three-electrode system with the electrode prepared using commercial activated carbon or UiO-66 samples as the working electrode with the area of $1 \mathrm{~cm}^{2}$; an $\mathrm{Ag} / \mathrm{AgCl}$ electrode and a platinum wire electrode were used as the reference electrode and the counter electrode, respectively, and the electrolyte solution was $1 \mathrm{~mol} / \mathrm{L} \mathrm{NaCl}$ solution. The cyclic voltammetry test and the AC impedance test were performed using an electrochemical workstation (CHI660E), using the abovedescribed experimental system. Within a certain range of voltages, the scanning rates of $0.2 \mathrm{~V} / \mathrm{s}, 0.1 \mathrm{~V} / \mathrm{s}, 0.05 \mathrm{~V} / \mathrm{s}$, $0.02 \mathrm{~V} / \mathrm{s}$, and $0.01 \mathrm{~V} / \mathrm{s}$ were applied to the electrodes, and 
the response currents of the electrodes were measured at the same time, allowing to obtain current-voltage curves [31]. The specific capacitance $C$ was calculated using the following equation:

$$
C=\int \frac{I d V}{2 v \Delta V m},
$$

where $C$ (in farads) represents the specific capacitance, $I$ (in amperes) represents the response current density, $\Delta V$ (in volts) is the potential window, $v$ (in volts/second) is the potential scan rate, and $m$ (in grams) is the total mass of the electrode materials.

The AC impedance test used the same three-electrode system. The voltage was $0.005 \mathrm{~V}$, and the frequency ranged from $0.01 \mathrm{~Hz}$ to $10000 \mathrm{~Hz}$. The AC impedance spectra were obtained.

2.4. Electrosorption-Desorption Experiment. The electrosorption-desorption experiment of the corresponding solution was performed on the electrode made of commercial activated carbon and the prepared UiO-66 samples, to determine the phosphate removal of the prepared UiO-66 materials with respect to phosphate. Commercial activated carbon or the prepared UiO-66 samples, the conductive agent (carbon black), and the polytetrafluoroethylene dilute binder (PVDF) were mixed evenly, according to the mass ratio of $8: 1: 1$. A suitable amount of the dimethylacetamide solvent was added and mixed for 4 hours, under magnetic stirring, to form a slurry. The slurry was evenly spread on a $25 \mathrm{~m}^{2}$ area graphite plate and dried in a vacuum oven at $80^{\circ} \mathrm{C}$ for 20 hours.

The phosphate removal and the electrosorption capacity were the main indicators of the desalination capacity of the prepared UiO-66 materials with respect to the electrosorption desalination. The phosphate removal $\eta$ was computed as follows:

$$
\eta=\frac{C_{0}-C_{t}}{C_{0}} \times 100 \%
$$

where $C_{0}$ (in $\mathrm{mg} / \mathrm{L}$ ) is the concentration of sodium dihydrogen phosphate in the initial solution, and $C_{t}($ in $\mathrm{mg} / \mathrm{L}$ ) is the concentration of sodium dihydrogen phosphate in the solution after $t$ ( $\mathrm{min}$ ) operation in the capacitive phosphate removal process.

The calculation formula of electrosorption capacity $q$ $(\mathrm{mg} / \mathrm{g})$ is as follows:

$$
q=\left(c_{0}-c_{t}\right) \frac{V}{m}
$$

where $V(\mathrm{~L})$ is the volume of the treatment solution and $m$ ( $g$ ) is the mass of the effective electrode material in the electrode.

\section{Results and Discussion}

3.1. Characterization of UiO-66. Regulators are an important factor that affects the synthesis of MOFs. Different types and amounts of regulators affect the synthesis environment of crystal materials, nucleation and growth of crystals, and further affect the relative crystallinity and grain size of MOFs $[32,33]$. In the coordination process of metal ions and organic ligands, the regulator replaces part of the organic ligand in the metal skeleton.

Figure 1 shows the XRD spectra of $\mathrm{UiO}-66$ (hydrochloric acid), UiO-66 (acetic acid), and single-crystal simulated XRD spectrum of the UiO-66 powder, which was reported by Andreas et al. [34]. The peaks for UiO-66 (hydrochloric acid) and UiO-66 (acetic acid) are consistent with the characteristic peaks in the simulated spectrum of UiO-66 and have the same relative intensities and shapes; in addition, there are almost no other miscellaneous peaks. The XRD spectra of UiO-66 (hydrochloric acid) and UiO-66 (acetic acid) exhibit slight fluctuations in the $50^{\circ}-90^{\circ}$ range, which may be caused by the uneven surface of the sample on the glass slide during the sample preparation. The XRD spectra of UiO-66 (hydrochloric acid) and UiO-66 (acetic acid) all exhibit characteristic peaks at $2 \theta=7.36^{\circ}, 8.48^{\circ}, 12.04^{\circ}, 14.15^{\circ}, 17.08^{\circ}, 22.25^{\circ}, 25.68^{\circ}$, and $33.12^{\circ}$, corresponding to the (111), (002), (113), (004), (115), (224), and (137) crystal faces, respectively. So, UiO-66 was successfully synthesized in this experiment, exhibiting good crystallinity, high symmetry, good topological structure, and porous cage structure in the skeleton. The relative intensities of the characteristic diffraction peaks of UiO-66 (acetic acid) are weaker than those of UiO-66 (hydrochloric acid), indicating that UiO66 (acetic acid) has poor crystallinity but features more surface adsorption sites.

Figures 2(a) and 2(b) show the SEM characterization of the UiO-66 (acetic acid) and UiO-66 (hydrochloric acid) samples, respectively. The UiO-66 particles, with the acetic acid as the regulator, are octahedral, with uniform distribution of particles and with a particle size of $30 \mathrm{~nm}$ (Figure 2(a)). Smaller-size UiO-66 particles tend to agglomerate and provide a larger specific surface area, which significantly increases the electrochemical reaction area. The shape of the UiO-66 particles with the hydrochloric acid as the regulator is irregular octahedron and varies greatly. The particle sizes are mostly in the 100$200 \mathrm{~nm}$ range (Figure 2(b)). The dispersion of the UiO66 particles (hydrochloric acid) is good, and different-size particles form partial clusters.

The UiO-66 particles, prepared with the acetic acid as the regulator, are highly symmetric (Figures 2(c) and 2(d)). A $\mathrm{Zr}_{6}$ octahedral nucleus is coordinated with 12 terephthalic acid ligands to form tetrahedral and octahedral cages. Each octahedral cage is connected with a tetrahedral cage on eight surfaces, and this connection extends continuously in the three-dimensional space. The UiO-66 particles prepared with the hydrochloric acid as the regulator exhibit larger crystallinity, larger particle size, and larger particle dispersion. 


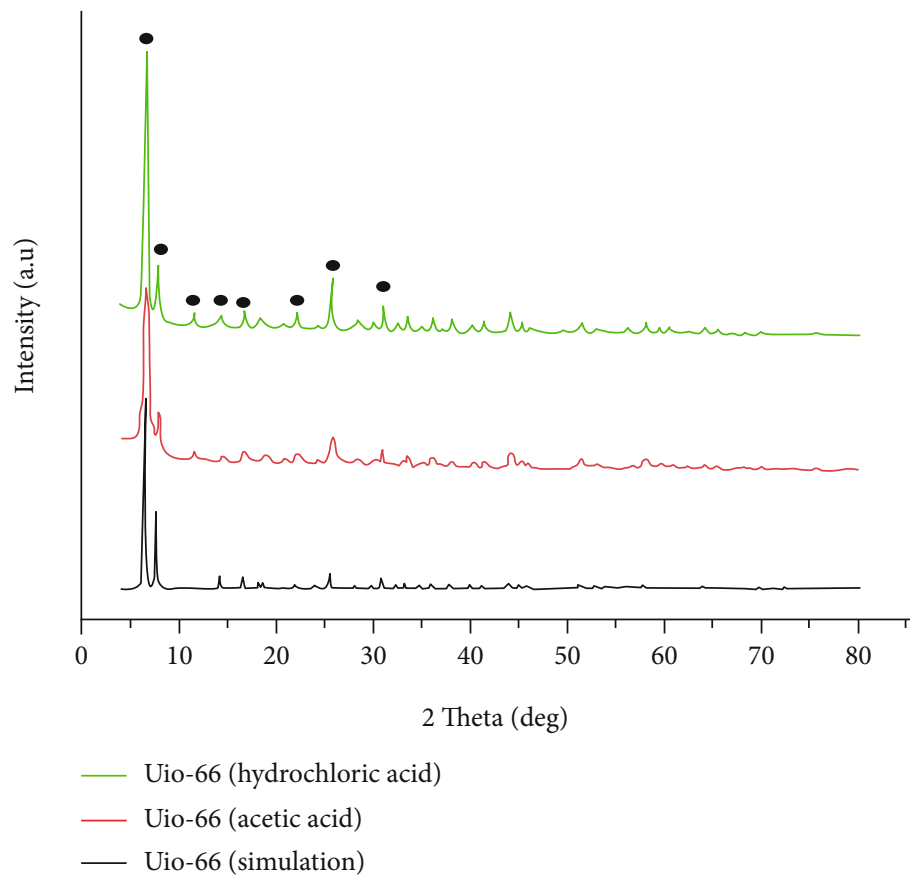

Figure 1: XRD spectra (-UiO-66 (hydrochloric acid); -UiO-66 (acetic acid); -UiO-66 (simulation)).

The SEM and TEM images show that, by adding the acetic acid as a regulator, the obtained UiO-66 material has uniform distribution of uniform-size and small-size particles. The UiO-66 sample particles with the hydrochloric acid as a regulator exhibit dispersion, non-uniform-size particles, and a wide range of particle sizes. To conclude, UiO-66 materials with different-size particles can be prepared by using different regulators.

3.2. Electrochemical Performance Test Result Analysis. At the scanning rate of $0.01 \mathrm{~V} / \mathrm{s}$, the shape of the cyclic voltammetry curve for commercial activated carbon is most similar to that of a parallel quadrilateral. With increasing the scanning rate, the shape of the curve gradually deviates from the parallelogram one and turns into an ellipse (Fig. AM1(a)). The main reasons for this are the decentralized capacitance effect and the ohmic voltage drop in the cyclic voltammetry test process. It takes a certain time for the current to reach a stable state. With increasing the scanning rate, the average capacitance decreases [35]. This happens because the slower the scanning speed is, the more time it takes for the pulse voltage to contact the micropore of the activated carbon electrode, and the larger the average capacitance is. On the contrary, if the scanning speed is fast and the time is too short, the pulse voltage cannot reach the micropore of the activated carbon electrode, and the capacitance is relatively low [27, 36].

The cyclic voltammetry curves for the UiO-66 (acetic acid) and UiO-66 (hydrochloric acid) materials are smooth and symmetrical (Figs. AM1(b) and AM1(c)). The cyclic voltammetry curves for the $\mathrm{UiO}-66$ (acetic acid) and $\mathrm{UiO}-$ 66 (hydrochloric acid) materials are most similar to those of parallelograms, at a scanning rate of $0.002 \mathrm{~V} / \mathrm{s}$. In this experiment, the capacities of commercial activated carbon, the UiO-66 (acetic acid), and the UiO-66 (hydrochloric acid) materials, at a scanning rate of $0.01 \mathrm{~V} / \mathrm{s}$, were, respectively, $33.01,2.18$, and 3.98 times higher than those at a scanning rate of $0.2 \mathrm{~V} / \mathrm{s}$. The scanning rate had the strongest effect for commercial activated carbon.

As shown in Fig. AM2, the capacitance of commercial activated carbon is higher than that of the UiO-66 (acetic acid) and UiO-66 (hydrochloric acid) materials. The main reason is that the effective contact area between the UiO66 particles and the conductive agent carbon black is smaller than that between commercial activated carbon and carbon black, and the conductivity of the material itself is slightly lower. In cyclic voltammetry, for scanning rates above $0.01 \mathrm{~V} / \mathrm{s}$, the specific capacitance of commercial activated carbon materials decays very fast, and the charge-discharge ratio performance is limited to a certain extent.

At a scanning rate of $0.01 \mathrm{~V} / \mathrm{s}$, the average capacitances of the UiO-66 (acetic acid) and UiO-66 (hydrochloric acid) materials are similar. However, with increasing the scanning rate, the attenuation of the average capacitance varies, and the average capacitance of the UiO-66 (hydrochloric acid) material decreases more (Figure 3). This may be owing to the influence of different regulators on the porosity of UiO66 . When the scanning rate is the same, the pores of UiO66 material with higher porosity will enter more pulse voltage.

The AC impedance spectra of the three different electrodes are shown in Fig. AM3. The EIS curves of commercial activated carbon and the two synthesized UiO-66 materials have similar shapes. They are composed of a half-circle in the high-frequency region and a slanted line in the low-frequency region, which may be caused by the surface roughness and pore inhomogeneity of the studied 


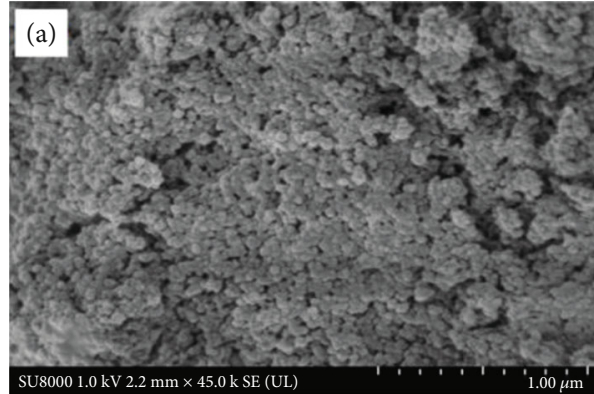

(a)

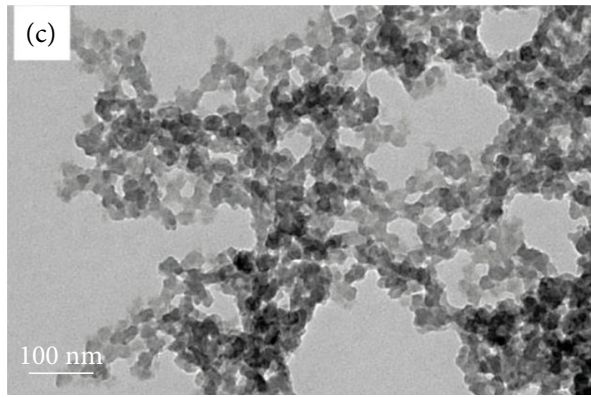

(c)

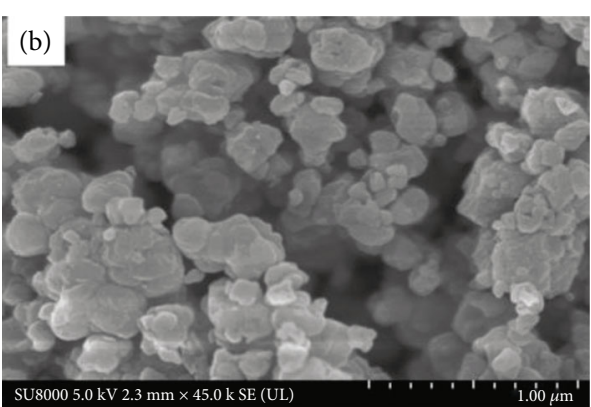

(b)

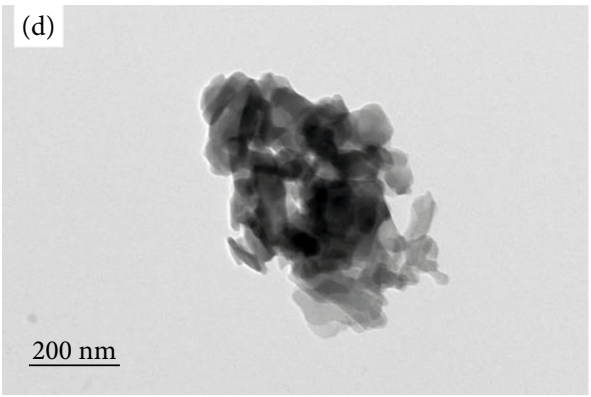

(d)

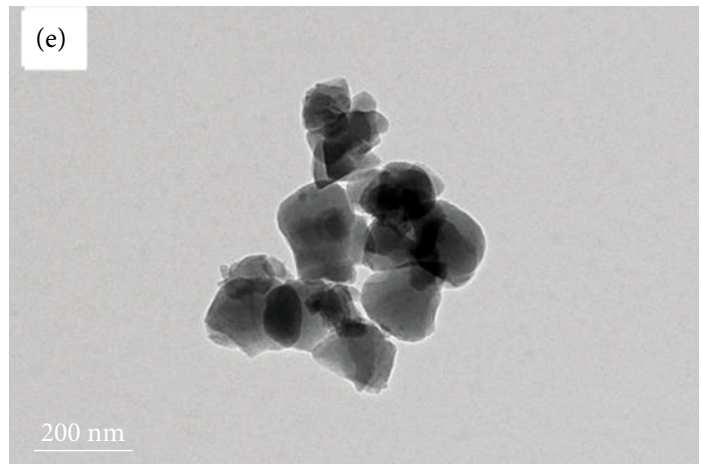

(e)

FIgURE 2: SEM and TEM characterization (SEM: (a) UiO-66 (acetic acid); (b) UiO-66 (hydrochloric acid); TEM: (c) UiO-66 (acetic acid); (d) UiO-66 (acetic acid); (e) UiO-66 (hydrochloric acid)).

electrodes that are made of porous materials. The highfrequency half-circle curve is determined by the electrolyte resistance, internal material resistance, and charge transfer resistance, while the low-frequency straight line is caused by the ionic diffusion of the electrolyte during charging and discharging, which is related to the capacitance performance of materials [35]. The semicircle in the highfrequency region reflects the charge transfer process during the electrochemical reaction. The diameter of the semicircle is called reaction resistance $\left(R_{\mathrm{ct}}\right)$ and is also known as the Faraday resistance [36]. Usually, if the reaction resistance of the electrode material is low, the internal resistance of the material's electrochemical reaction is low as well, and the charge transfer process can occur at the interface of the formed double layer, with excellent reaction kinetic characteristics.

Figs. AM3(a)-AM3(c) show typical Warburg impedance characteristic curves, which are determined by the mass transfer diffusion control [7]. To contrast Figs. AM3(b) and AM3(c), the semicircular curve for the UiO-66 $(\mathrm{HCl})$ material is almost a straight line. It may be that after the cyclic voltammetry test of the same nickel foam collector in the AC impedance test, most of the surface coating is removed, and only a small amount of the electrode conducting fluid is present on the foam nickel.

3.3. Phosphate Removal of Electrosorption Analysis. To determine whether the graphite plate electrodes made of the synthesized UiO-66 materials support desalination, $500 \mathrm{mg} / \mathrm{L}$ of the sodium chloride solution was prepared for desalination by electrosorption, and conductivity changes were observed. During 5 minutes of adsorption, the conductivity of the sodium chloride solution gradually decreased from $961 \mathrm{~s} / \mathrm{cm}$ to $943 \mathrm{~s} / \mathrm{cm}$ and remained unchanged for 8 minutes, reaching an equilibrium (Fig. AM4). After 27 minutes, the conductivity of the solution 


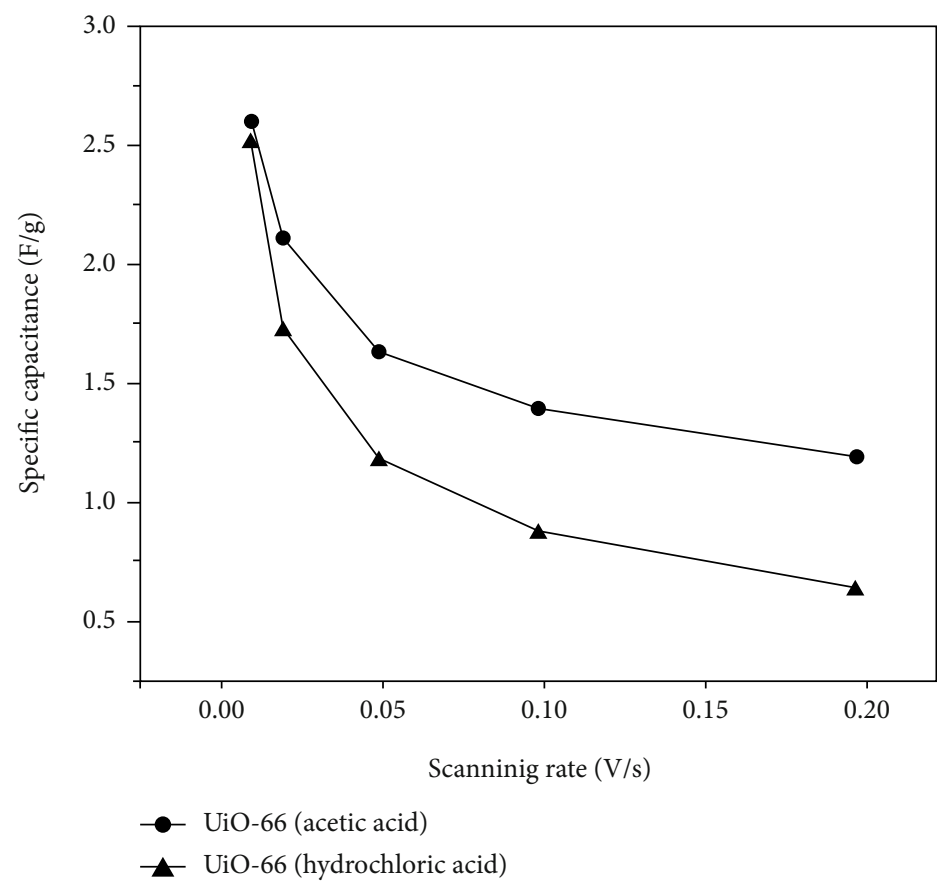

FIGURE 3: Specific capacitance changes of the two synthesized UiO-66 electrode materials, at different scanning rates (local magnification).

increased to $954 \mathrm{~s} / \mathrm{cm}$, and the ions adsorbed on the electrode were partly released into the original solution during the desorption process, with a desorption rate of $54 \%$. The results show that the graphite plate electrodes prepared from the synthesized UiO-66 materials exhibit good desalination performance, and the capacitance of the materials has a certain binding effect on $\mathrm{Na}^{+}, \mathrm{Mg}^{2+}$ plasma in water, which exhibits certain cyclic reversibility and regeneration performance.

Different concentrations of the sodium dihydrogen phosphate solution were used for the electrosorption testing. Figure 4 shows that the conductivity of the two synthesized UiO-66 samples in the process of desalination by electrosorption, at four different concentrations of the sodium dihydrogen phosphate solution, does not increase but decreases, which is inconsistent with the general electrosorption process. However, when the same UiO-66 sample electrode was electroadsorbed in the sodium chloride solution, its conductivity decreased, indicating that the graphite plate electrode had a certain desalination performance. It was suspected that salt ions were mixed into the sample material preparation process. Therefore, pure UiO-66 samples were directly adsorbed to observe changes in the conductivity during the adsorption process, for further research and analysis.

Adsorption experiments were performed by adding $0.1 \mathrm{~g}$ each of the two synthesized UiO-66 samples to the $100 \mathrm{~mL}$ sodium dihydrogen phosphate solution (Fig. AM5). For the synthesized UiO-66, the conductivity still increased during the adsorption process; however, in literature, the phosphate removal performance of the UiO-66 adsorbent has been studied, which suggests the feasibility of using this adsorbent in practical applications [37]. At the same time, commercial activated carbon exhibited a certain desalination effect when it was electroadsorbed with the sodium dihydrogen phosphate solution, and it is pure and free from impurities and other ions (additional material in Figs. AM6-AM9). In conclusion, it is reasonable to suspect that the prepared UiO-66 sample particles may have more salt ions attached to them, and the dissolution during adsorption results in an increase in their conductivity.

The conductivity values for the sodium dihydrogen phosphate solutions at different concentrations were determined at $25^{\circ} \mathrm{C}$. The results are listed in Table 1.

The conductivity of UiO-66 (acetic acid) solution and UiO-66 (hydrochloric acid) solution was $74.5 \mu \mathrm{s} / \mathrm{cm}$ and $58.7 \mu \mathrm{s} / \mathrm{cm}$, respectively. This indicated that salt ions had been attached to the sample particles. The conductivity after adsorption equilibrium was less than the sum of the conductivity of sodium dihydrogen phosphate solution and electrode material in the aqueous solution. It can be concluded that the UiO-66 sample prepared in this experiment has a certain desalination effect.

The removal of phosphate by the UiO-66 electrosorption has a certain effect (Figure 5 and Table 2), because the $-\mathrm{OH}$ functional group of its secondary structural unit has a good affinity with the phosphorus functional group [38]. Compared with the phosphate removal and adsorption capacity of the synthesized UiO-66 samples prepared by adding two different regulators, the UiO-66 (acetic acid) sample with uniform and small particle sizes, poor crystallinity, and more surface adsorption sites exhibited better adsorption efficiency for the same volume and 


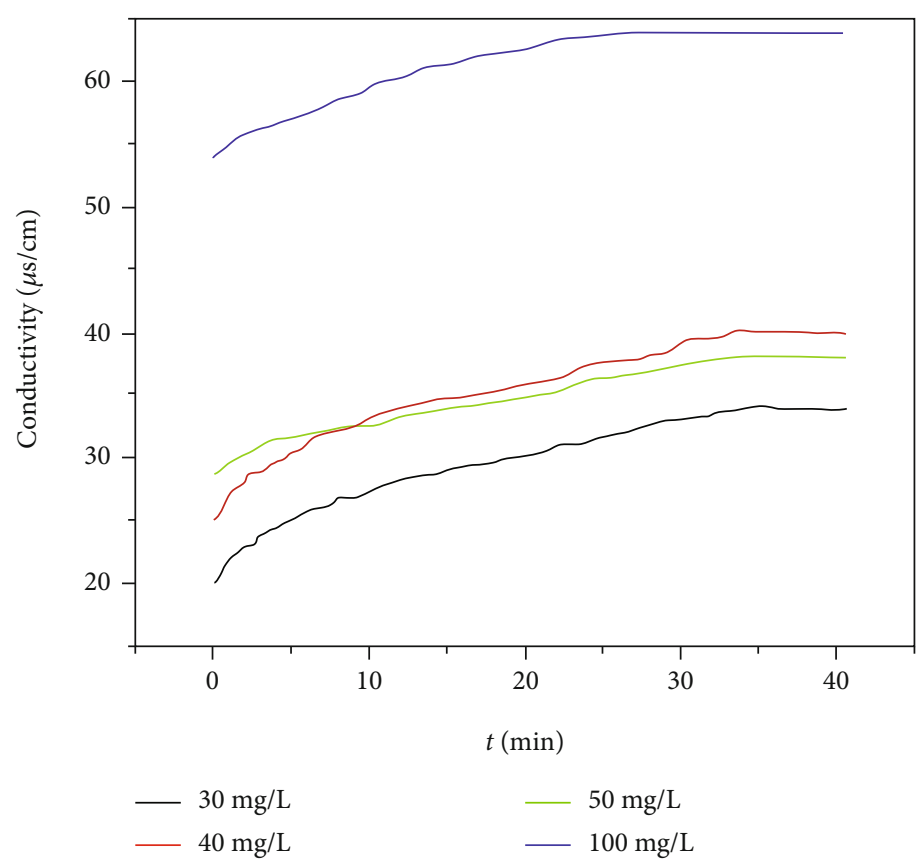

(a)

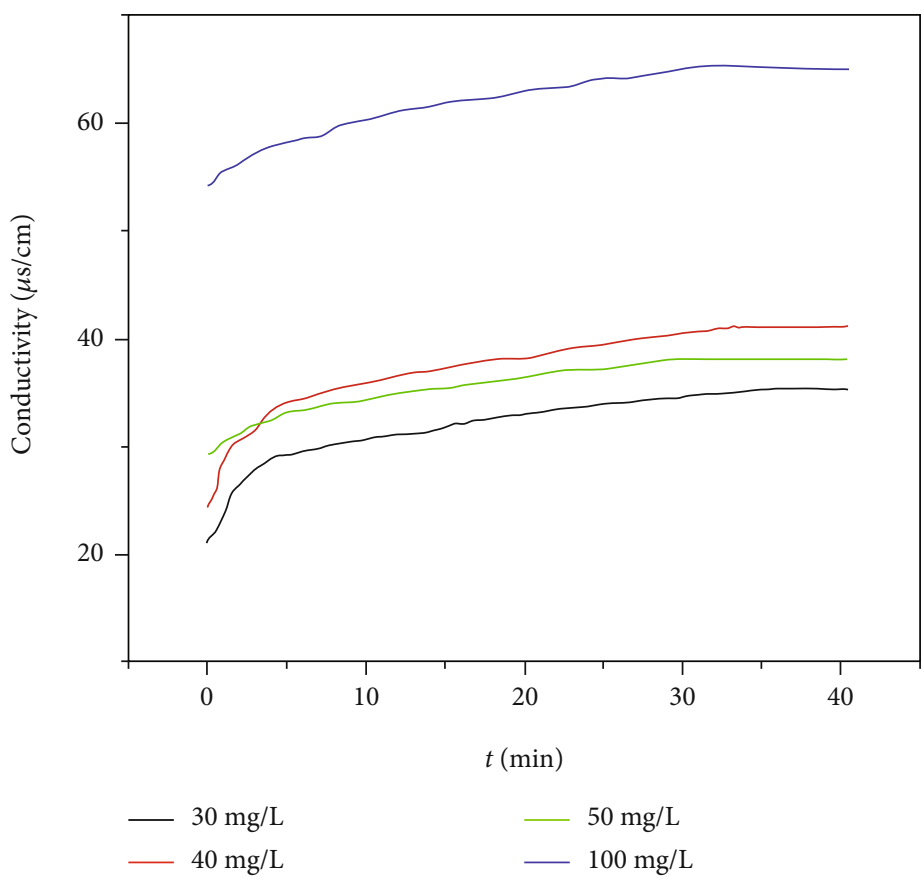

(b)

FIGURE 4: Electrosorption curves for the synthesized UiO-66 materials, for different $\mathrm{NaH}_{2} \mathrm{PO}_{4}$ solutions ((a) UiO-66 (acetic acid); (b) UiO-66 (hydrochloric acid)).

TABle 1: Conductivity of the sodium dihydrogen phosphate solution, at different concentrations, at $25^{\circ} \mathrm{C}$.

\begin{tabular}{lllllc}
\hline Concentration $(\mathrm{mg} / \mathrm{L})$ & 0 & 30 & 40 & 50 & 100 \\
Conductivity $(\mu \mathrm{s} / \mathrm{cm})$ & 2 & 18 & 25 & 33 & 58 \\
\hline
\end{tabular}

concentration of the sodium dihydrogen phosphate solution. The type of the regulator affects the morphology and structure of adsorbent materials, and the morphology and structure further affect the adsorptive properties of the adsorbent.

At the same time, the total phosphorus concentration in the solution after desorption by the UiO-66 electrosorption equilibrium was below the initial total phosphorus concentration. The reason for this is that most of the phosphorus 


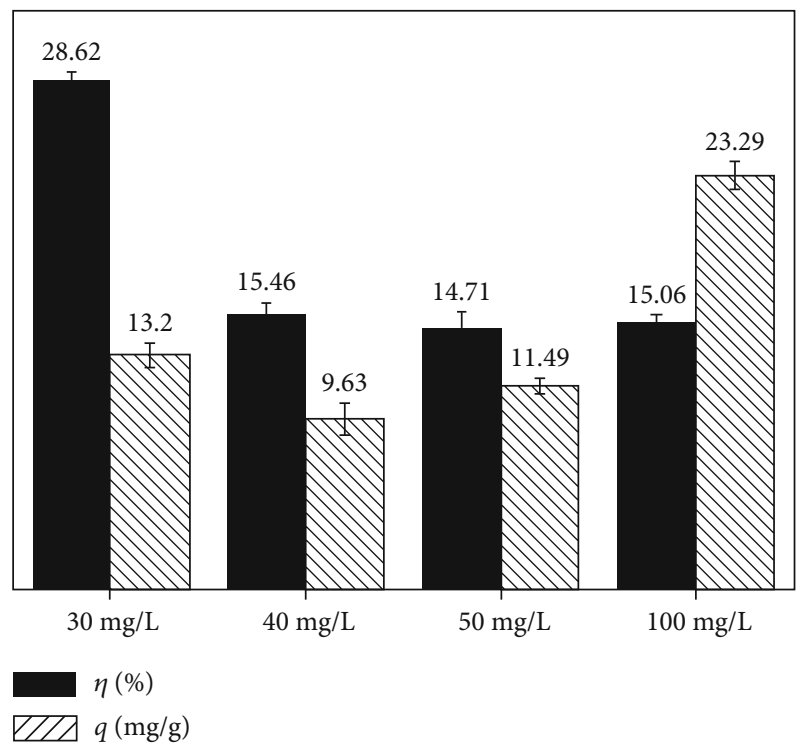

(a)

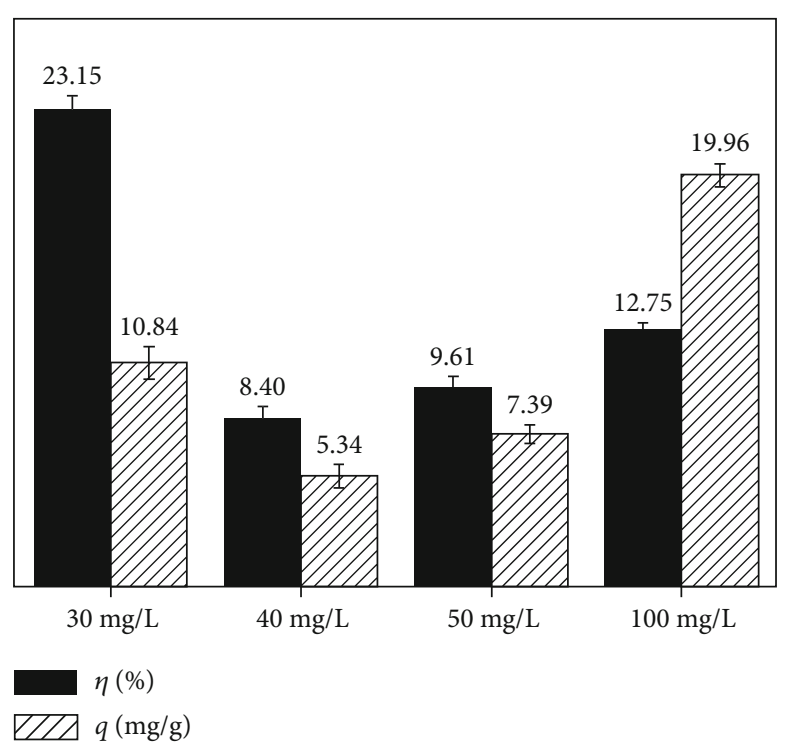

(b)

FIGURE 5: Desalination effect of the electrosorption of the synthesized UiO-66 samples, at different concentrations of the sodium dihydrogen phosphate solution ((a) UiO-66 (acetic acid); (b) UiO-66 (hydrochloric acid)).

TABLE 2: Total phosphorus concentration of the electrosorption of the synthesized UiO-66 samples, for different concentrations of the sodium dihydrogen phosphate solution.

\begin{tabular}{lccccccccc}
\hline & \multicolumn{3}{c}{ UiO-66 (acetic acid) } & \multicolumn{5}{c}{ UiO-66 (hydrochloric } \\
acid)
\end{tabular}

adsorption by UiO-66 is chemical complexation adsorption. Until now, linker exchange has been considered as the main driving force for phosphate adsorption on UiO-66-type MOFs [26]. There are some chemical bonds, which affect the regeneration of the adsorbent.

In Figure 6, it can be found that the phosphate removal and adsorption capacity of the same amount of effective UiO-66 sample in the same volume and concentration of sodium dihydrogen phosphate solution are higher than those of the electrosorption. It is likely that the synthesized UiO-66 particles have poor compatibility with the carbon black as a conductive agent when the phosphate is removed by electrosorption, the electrical contact is poor, and the crystal grains do not completely infiltrate the water body, thus, negatively affecting adsorption. After desalination by electrosorption, the ions adsorbed on the electrode return back to the solution, and a double-layer electrosorption-desorption cycle facilitates the engineering utilization of adsorbents. The cyclic reversibility and regeneration performance of the UiO-66 materials are reasonably utilized by electrosorption,

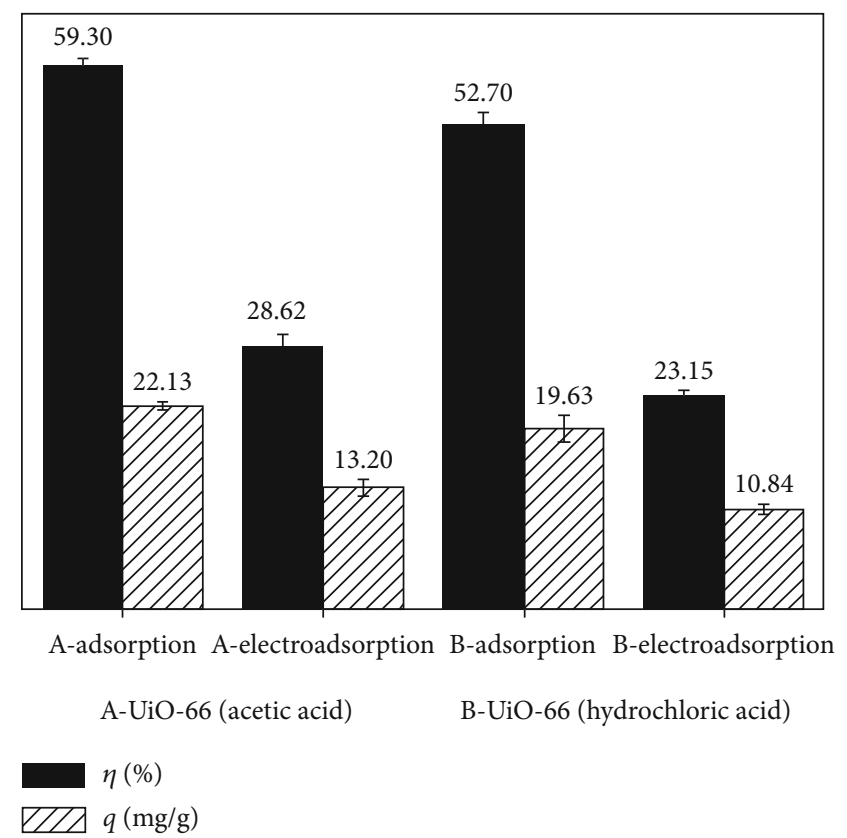

FIgURE 6: Comparison of the phosphate removal of the two synthesized UiO-66 samples, adsorbed and electrosorbed in the $30 \mathrm{mg} / \mathrm{L}$ sodium dihydrogen phosphate solution.

which is convenient for desorption, to regenerate the adsorbent and to reduce the cost of treatment.

\section{Conclusion}

The characterization results show that the surface morphology of UiO-66 (acetic acid) is better than that of UiO-66 (hydrochloric acid). The synthesized material featured 
uniform-size and small-size particles, rough and porous surface, and poor crystallinity and had better surface adsorption potential, meeting the requirements of electrosorption for electrode materials. The results of the cyclic voltammetry and AC impedance show that commercial activated carbon had higher specific capacitance than the two UiO-66 materials. When the scanning rate was $10 \mathrm{mV} / \mathrm{s}$ for the $1 \mathrm{~mol} / \mathrm{L}$ $\mathrm{NaCl}$ electrolyte, the capacitance reached $84.84 \mathrm{~F} / \mathrm{g}$. In the process of electrosorption, when the initial concentration of sodium dihydrogen phosphate solution was $30 \mathrm{mg} / \mathrm{L}$, $40 \mathrm{mg} / \mathrm{L}, 50 \mathrm{mg} / \mathrm{L}$, and $100 \mathrm{mg} / \mathrm{L}$, the phosphate adsorption capacity of UiO-66 (acetic acid) was $13.20 \mathrm{mg} / \mathrm{g}, 9.63 \mathrm{mg} / \mathrm{g}$, $11.49 \mathrm{mg} / \mathrm{g}$, and $23.29 \mathrm{mg} / \mathrm{g}$, and that of UiO-66 (hydrochloric acid) was $10.84 \mathrm{mg} / \mathrm{g}, 5.34 \mathrm{mg} / \mathrm{g}, \quad 7.39 \mathrm{mg} / \mathrm{g}$, and $19.96 \mathrm{mg} / \mathrm{g}$, respectively. The results showed that the synthesized UiO-66 (acetic acid) samples with uniform-size and small-size particles, poor crystallinity, and more surface adsorption sites exhibited better adsorption efficiency and adsorption capacity for the same volume and the same concentration of the sodium dihydrogen phosphate solution. When the concentration of sodium dihydrogen phosphate solution was $30 \mathrm{mg} / \mathrm{L}$, the phosphate removal efficiency of UiO-66 (acetic acid) and UiO-66 (hydrochloric acid) was 59.3\% and $52.7 \%$, and the adsorption capacities were $22.13 \mathrm{mg} / \mathrm{g}$ and $19.63 \mathrm{mg} / \mathrm{g}$. It can be seen that under the same conditions, the phosphate removal and adsorption capacity of electrosorption were lower than those of adsorption. The electrosorption process of the synthesized UiO-66 material was reversible and exhibited good regeneration performance. It is easy to reuse the adsorbent, for separation and recovery of phosphate, which can reduce the cost of wastewater treatment and is likely to be widely adopted for various engineering applications.

\section{Data Availability}

All authors agreed to state that required data and relevant materials will be available for further validation of the results presented.

\section{Conflicts of Interest}

The authors declared no potential conflicts of interest with respect to the research, authorship, and/or publication of this article.

\section{Acknowledgments}

We thank Elsevier for its linguistic assistance during the preparation of this manuscript. This work was supported by the Fundamental Research Funds for the Central Universities (N180104015).

\section{Supplementary Materials}

Figure AM1: current-voltage curves, for the scanning rates of $10 \mathrm{mV} / \mathrm{s}, 20 \mathrm{mV} / \mathrm{s}, 50 \mathrm{mV} / \mathrm{s}, 100 \mathrm{mV} / \mathrm{s}$, and $200 \mathrm{mV} / \mathrm{s}$. ((a) Commercial activated carbon, scanning range $=0-7 \mathrm{~V}, m$ $=0.02024 \mathrm{~g}$; (b) UiO-66 (acetic acid), scanning range $=-$
$0.2--0.11 \mathrm{~V}, m=0.01032 \mathrm{~g}$; (c) UiO-66 (hydrochloric acid), scanning range $=-0.2--0.11 \mathrm{~V}, m=0.01031 \mathrm{~g})$. Figure AM2: specific capacitance change, for the three electrode materials, for different scanning rates. Figure AM3: AC impedance spectra of three different materials ((a) commercial activated carbon; (b) UiO-66 (acetic acid); (c) UiO-66 (hydrochloric acid)). Figure AM4: electrosorption-desorption curve of the $\mathrm{NaCl}$ solution with the initial concentration of $500 \mathrm{mg} / \mathrm{L}$. Figure AM5: adsorption curve of the UiO-66 synthesized sample in the $30 \mathrm{mg} / \mathrm{L}$ sodium dihydrogen phosphate solution ((a) UiO66 (acetic acid); (b) UiO-66 (hydrochloric acid)). Figure AM6: electrosorption-desorption curve of $\mathrm{NaCl}$ solution with an initial concentration of $500 \mathrm{mg} / \mathrm{L}$. Figure AM7: electrosorptiondesorption curve of $\mathrm{NaH}_{2} \mathrm{PO}_{4}$ solution with an initial concentration of $30 \mathrm{mg} / \mathrm{L}$. Figure AM8: electrosorption-desorption curve of $\mathrm{NaH}_{2} \mathrm{PO}_{4}$ solution with an initial concentration of $40 \mathrm{mg} / \mathrm{L}$. Figure AM9: electrosorption-desorption curve of $\mathrm{NaH}_{2} \mathrm{PO}_{4}$ solution with an initial concentration of $50 \mathrm{mg} / \mathrm{L}$. (Supplementary Materials)

\section{References}

[1] Y. J. Dai, M. Liu, J. J. Li et al., "A review on pollution situation and treatment methods of tetracycline in groundwater," Separation Science and Technology, vol. 55, no. 5, pp. 1005-1021, 2020.

[2] K. Sukačová, M. Trtílek, and T. Rataj, "Phosphorus removal using a microalgal biofilm in a new biofilm photobioreactor for tertiary wastewater treatment," Water Research, vol. 71, pp. 55-63, 2015.

[3] G. R. Sun, C. Y. Zhang, W. Li, L. Yuan, S. He, and L. Wang, "Effect of chemical dose on phosphorus removal and membrane fouling control in a UCT-MBR," Frontiers of Environmental Science \& Engineering, vol. 13, no. 1, pp. 27-37, 2019.

[4] B. Ji, W. Chen, J. Fan, J. Wang, S. W. Xie, and H. J. Song, "Research progress on using chemical and biological coordination method to remove phosphorus from wastewater," Modern Chemical Industry, vol. 37, no. 5, 2017.

[5] K. V. Lo, I. Tunile, H. J. Tan et al., "Microwave enhanced advanced oxidation treatment of sewage sludge from the membrane-enhanced biological phosphorus removal process," Separation and Purification Technology, vol. 197, pp. 202-209, 2018.

[6] J. H. Lv and L. J. Yuan, "Effects of chemical phosphate precipitation in the sidestream process on biological phosphorus removal at the anaerobic stage in an anaerobic-aerobic sequencing batch reactor," Desalination and Water Treatment, vol. 54, no. 11, pp. 3011-3019, 2015.

[7] F. Yang, W. Y. Li, and B. H. J. Tang, "Facile synthesis of amorphous UiO-66 (Zr-MOF) for supercapacitor application," Journal of Alloys and Compounds, vol. 733, pp. 8-14, 2018.

[8] D. Crutchik, S. Rodrigues, D. Ruddle, and J. M. Garrido, "Evaluation of a low-cost magnesium product for phosphorus recovery by struvite crystallization," Journal of Chemical Technology \& Biotechnology, vol. 93, no. 4, pp. 1012-1021, 2018.

[9] H. L. Dai, X. W. Lu, Y. H. Peng, Z. Yang, and H. Zhsssu, "Effects of supersaturation control strategies on hydroxyapatite (HAP) crystallization for phosphorus recovery from wastewater," Environmental Science and Pollution Research, vol. 24, no. 6, pp. 5791-5799, 2017. 
[10] B. Lu, J. C. Xu, M. Zhang, W. Pang, and L. Xie, "Phosphorus removal and recovery from wastewater by highly efficient struvite crystallization in an improved fluidized bed reactor," Korean Journal of Chemical Engineering, vol. 34, no. 11, pp. 2879-2885, 2017.

[11] Y. J. Shih, R. R. M. Abarca, M. D. G. de Luna, Y. H. Huang, and M. C. Lu, "Recovery of phosphorus from synthetic wastewaters by struvite crystallization in a fluidized-bed reactor: effects of $\mathrm{pH}$, phosphate concentration and coexisting ions," Chemosphere, vol. 173, pp. 466-473, 2017.

[12] M. M. Abd el- Latif and A. M. Ibrahim, "Adsorption, kinetic and equilibrium studies on removal of basic dye from aqueous solutions using hydrolyzed oak sawdust," Desalination and Water Treatment, vol. 6, no. 1-3, pp. 252-268, 2009.

[13] Y. Fan, Y. W. Li, D. Wu, C. Li, and H. Kong, "Application of zeolite/hydrous zirconia composite as a novel sediment capping material to immobilize phosphorus," Water Research, vol. 123, pp. 1-11, 2017.

[14] A. M. E. Khalil, O. Eljamal, T. W. M. Amen, Y. Sugihara, and N. Matsunaga, "Optimized nano-scale zero-valent iron supported on treated activated carbon for enhanced nitrate and phosphate removal from water," Chemical Engineering Journal, vol. 309, pp. 349-365, 2017.

[15] W. P. Xiong, J. Tong, Z. H. Yang et al., “Adsorption of phosphate from aqueous solution using iron-zirconium modified activated carbon nanofiber: performance and mechanism," Journal of Colloid and Interface Science, vol. 493, pp. 17-23, 2017.

[16] M. Kandiah, M. H. Nilsen, S. Usseglio et al., "Synthesis and stability of tagged UiO-66 Zr-MOFs," Chemistry of Materials, vol. 22, no. 24, pp. 6632-6640, 2010.

[17] C. H. Wang, X. L. Liu, J. P. Chen, and K. Li, "Superior removal of arsenic from water with zirconium metal-organic framework UiO-66," Science Reports, vol. 5, no. 1, 2015.

[18] K. K. Yee, N. Reimer, J. Liu et al., "Effective mercury sorption by thiol-laced metal-organic frameworks: in strong acid and the vapor phase," Journal of the American Chemical Society, vol. 135, no. 21, pp. 7795-7798, 2013.

[19] Q. L. Zhu and Q. Xu, "Metal-organic framework composites," Chemical Society Reviews, vol. 43, no. 16, pp. 5468-5512, 2014.

[20] J. Cavka, S. Jakobsen, U. Olsbye et al., "A new zirconium inorganic building brick forming metal organic frameworks with exceptional stability," Journal of the American Chemical Society, vol. 130, no. 42, pp. 13850-13851, 2008.

[21] Y. C. Lin, Q. J. Yan, C. L. Kong, and L. Chen, "Polyethyleneimine incorporated metal-organic frameworks adsorbent for highly selective $\mathrm{CO}_{2}$ capture," Scientific Reports, vol. 3, no. 1, article 1859, 2013.

[22] F. Vermoortele, B. Bueken, G. le Bars et al., "Synthesis modulation as a tool to increase the catalytic activity of metalorganic frameworks: the unique case of UiO-66(Zr)," Journal of the American Chemical Society, vol. 135, no. 31, pp. 11465-11468, 2013.

[23] H. Qiu, M. C. Ye, Q. Q. Zeng et al., "Fabrication of agricultural waste supported UiO-66 nanoparticles with high utilization in phosphate removal from water," Chemical Engineering Journal, vol. 360, pp. 621-630, 2019.

[24] K. A. Lin, S. Y. Chen, and A. P. Jochems, "Zirconium-based metal organic frameworks: highly selective adsorbents for removal of phosphate from water and urine," Materials Chemistry and Physics, vol. 160, pp. 168-176, 2015.
[25] X. Y. Min, X. Wu, P. H. Shao, Z. Ren, L. Ding, and X. Luo, "Ultra-high capacity of lanthanum-doped UiO-66 for phosphate capture: unusual doping of lanthanum by the reduction of coordination number," Chemical Engineering Journal, vol. 358, pp. 321-330, 2019.

[26] L. J. Wang, X. H. Wen, J. Li, P. Zeng, Y. Song, and H. Yu, "Roles of defects and linker exchange in phosphate adsorption on UiO-66 type metal organic frameworks: influence of phosphate concentration," Chemical Engineering Journal, vol. 405, article 126681, 2021.

[27] Y. Liu, X. Xu, M. Wang, T. Lu, Z. Sun, and L. Pan, "Metalorganic framework-derived porous carbon polyhedra for highly efficient capacitive deionization," Chemical Communications, vol. 51, no. 60, pp. 12020-12023, 2015.

[28] N. Areerachakul, S. Vigneswaran, H. H. Ngo, and J. Kandasamy, "Granular activated carbon (GAC) adsorption-photocatalysis hybrid system in the removal of herbicide from water," Separation and Purification Technology, vol. 55, no. 2, pp. 206-211, 2007.

[29] G. Rasines, P. Lavela, C. Macías, M. Haro, C. O. Ania, and J. L. Tirado, "Electrochemical response of carbon aerogel electrodes in saline water," Journal of Electroanalytical Chemistry, vol. 671, pp. 92-98, 2012.

[30] W. Xing, H. H. Ngo, S. H. Kim, W. S. Guo, and P. Hagare, "Adsorption and bioadsorption of granular activated carbon (GAC) for dissolved organic carbon (DOC) removal in wastewater," Bioresource Technology, vol. 99, no. 18, pp. 8674-8678, 2008.

[31] G. Wang, C. Pan, L. P. Wang et al., "Activated carbon nanofiber webs made by electrospinning for capacitive deionization," Electrochimica Acta, vol. 69, pp. 65-70, 2012.

[32] Y. S. Li, X. K. Luo, H. T. Xu, and L. Zhen, "Preparation and catalytic performance and supported catalysts Au(Pd)@UIO-66," Journal of East China University of Science and Technology(Natural Science Edition), vol. 43, pp. 749-755, 2017.

[33] Z. Z. Hu and D. Zhao, "De facto methodologies toward the synthesis and scale-up production of UiO-66-type metalorganic frameworks and membrane materials," Dalton Transactions, vol. 44, no. 44, pp. 19018-19040, 2015.

[34] A. Schaate, P. Roy, A. Godt et al., "Modulated synthesis of Zrbased metal-organic frameworks: from nano to single crystals," Chemistry - A European Journal, vol. 17, no. 24, pp. 6643-6651, 2011.

[35] S. Diring, S. Furukawa, Y. Takashima, T. Tsuruoka, and S. Kitagawa, "Controlled multiscale synthesis of porous coordination polymer in nano/micro regimes," Chemistry of Materials, vol. 22, no. 16, pp. 4531-4538, 2010.

[36] P. M. Biesheuvel, S. Porada, M. Levi, and M. Z. Bazant, "Attractive forces in microporous carbon electrodes for capacitive deionization," Journal of Solid State Electrochemistry, vol. 18, no. 5, pp. 1365-1376, 2014.

[37] E. Zong, D. Wei, H. Q. Wan, S. Zheng, Z. Xu, and D. Zhu, "Adsorptive removal of phosphate ions from aqueous solution using zirconia- functionalized graphite oxide," Chemical Engineering Journal, vol. 221, pp. 193-203, 2013.

[38] W. Fu-Xue, W. Chong-Chen, W. Peng, and X. Bi-Cong, "Syntheses and applications of UiO series of MOFs," Chinese Journal of Inorganic Chemistry, vol. 33, no. 5, pp. 713-737, 2017. 